Anuario Latinoamericano Ciencias Políticas

y Relaciones Internacionales

vol. 3, 2016

pp. $219-240$

\section{Ayotzinapa. Entre la fragilidad institucional y la violencia del crimen organizado}

\section{Ayotzinapa. Between institutional fragility and violence of organized crime}

\author{
Gabino Solano Ramírez \\ INSTITUTO INTERNACIONAL DE ESTUDIOS POLÍTICOS AVANZADOS UNIVERSIDAD \\ AUTÓNOMA DE GUERRERO, MÉXICO \\ $\triangle$ gabinosln@gmail.com \\ José Carlos Luque Brazán \\ COLEGIO DE CIENCIAS SOCIALES Y HUMANIDADES \\ UNIVERSIDAD AUTÓNOMA DE LA CIUDAD DE MÉXICO, MÉXICO \\ $\triangle$ jose.luque@uacm.edu.mx. \\ Hortensia Gracida González \\ FACULTAD DE CIENCIAS DE LA EDUCACIÓN \\ UNIVERSIDAD AUTÓNOMA DE GUERRERO, MÉXICO \\ $\triangle$ tenchis@yahool.com
}

\section{RESUMEN}

El propósito de este trabajo es explorar las líneas comunicantes entre el acontecimiento denominado "Ayotzinapa" (ocurrido el 26 y 27 de septiembre en Iguala, Guerrero, donde 43 estudiantes de la Escuela Normal Rural de Ayotzinapa fueron desaparecidos), la inseguridad y violencia delincuencial asociada a la presencia de grupos delictivos organizados, y la fragilidad institucional de las estructuras de poder municipal para hacer frente a la amenaza que significan las organizaciones criminales en estados como Guerrero.

Se argumenta que este suceso fue posible debido a las limitaciones del cambio político democrático en México, caracterizado como insuficiente y descompensado, sobre todo en las instituciones municipales, las cuales, paulatinamente, han cedido espacio a la creciente influencia de grupos delictivos organizados.

PALABRAS CLAVE: Ayotzinapa, fragilidad institucional, violencia, grupos delictivos organizados, Guerrero, México.

\footnotetext{
ABSTRACT

The purpose of this paper is to explore the connecting lines between the event called "Ayotzinapa" (which occurred on 26 and 27 September in Iguala, Guerrero, where 43 students of the Rural Normal School Ayotzinapa were missing), insecurity and
}

DOI: $10.17951 / \mathrm{al} .2016 .3 .219$ 
criminal violence associated to the presence of organized criminal groups, and institutional fragility of the structures of municipal power to deal with the threat posed by criminal organizations in states like Guerrero.

It is argued that this event was possible due to the limitations of democratic political change in Mexico, considered insufficient and unbalanced, especially in municipal institutions, which gradually have given way to the growing influence of organized criminal groups.

KEY WORDS: Ayotzinapa, institutional fragility, violence, organized criminal groups, Guerrero, Mexico.

\section{Introducción}

Los hechos de violencia ${ }^{1}$ generados por el crimen organizado en el marco de la debilidad institucional en México han sido cuantiosos. Según los datos proporcionados por el Relator Especial de Naciones Unidas sobre ejecuciones extrajudiciales, sumarias y arbitrarias, durante el periodo de la denominada guerra contra el narco en México (2006 y 2014), ocurrieron 102.906 homicidios intencionales, 4.055 denuncias ante la PGR por tortura, 26.798 personas desaparecidas y 8.595 personas detenidas arbitrariamente bajo la figura de arraigo. ${ }^{2}$ En este marco se dio el trágico suceso de Ayotzinapa, donde perdieron la vida 6 personas y 43 estudiantes de la Escuela Normal Rural "Raúl Isidro Burgos" ubicada en Ayotzinapa, municipio de Tixtla, Guerrero. Este hecho representa un punto de inflexión en la historia política de México y se suma a los diferentes episodios de violencia política y violaciones recurrentes a los derechos humanos que se han registrado en Guerrero, entre las que sobresalen: la "guerra sucia" en los años setenta en contra de los movimientos guerrilleros de aquella época; la matanza de 20 estudiantes en Chilpancingo ordenada por Caballero Aburto en 1960; los 17 campesinos asesinados en Aguas Blancas en 1995, siendo gobernador Rubén Figueroa Alcocer; y, en 1998, en la comunidad El Charco, Ayutla, la ejecución por el ejército de 11 campesinos indígenas, durante el gobierno interino de Ángel Aguirre.

A partir de 2006, con la declarada "Guerra contra el narcotráfico", se inició otro ciclo de violencia, cuyo distintivo es la proliferación de organizaciones criminales, vinculadas al tráfico de drogas y otros delitos. Organizaciones criminales paulatinamente se han constituido en un poder fáctico que desafía la

1 La violencia generada por el crimen organizado se caracteriza por lo siguiente: "el agresor puede ser uno mismo, otra persona o un grupo reducido de personas, un grupo organizado (como por ejemplo las mafias). Que responde a un patrón empresarial ya que está formado por grupos de personas claramente estructurados con la característica de tener como objetivo el enriquecimiento ilegal de sus miembros a costa de la sociedad". (Romero, Loza y Machorro 2013: 3)

2 En los párrafos siguientes se presentará en extenso la información complementaria al respecto. 
presencia del Estado en numerosas regiones de la entidad y ha provocado la mayor crisis de seguridad desde la época posrevolucionaria, si se mide a través de los indicadores delictivos de alto impacto que registra el Secretariado Ejecutivo del Sistema Nacional de Seguridad Pública (SESNSP). ${ }^{3}$

El largo historial de violencia y la grave crisis de seguridad que se vive en el país, y con mayor crudeza en Guerrero, hace más complejo cualquier acercamiento con fines explicativos al acontecimiento de Ayotzinapa. Representa un serio desafío analítico para las ciencias sociales respecto a sus repercusiones sociopolíticas, en particular, su incidencia en el funcionamiento de los procesos políticos e institucionales del Estado mexicano. Así, las explicaciones de lo sucedido en Ayotzinapa giran en torno a dos grandes enfoques analíticos, influenciados desde la disputa que sucede en la arena pública, que ubican sus orígenes en dos situaciones críticas presentes en la realidad guerrerense y mexicana. Los que vinculan a este hecho con la disputa territorial mantenida por las organizaciones criminales en la entidad y en el país, que en el caso de Iguala representan las organizaciones de los Guerreros Unidos y Los Rojos, creen que la desaparición de los 43 normalistas fue perpetrada por una de las organizaciones delictivas que controlan este municipio: Guerreros Unidos. Esta es la tesis que defiende la Procuraduría General de la República (PGR 2015: 2). Otros afirman que este hecho sólo pudo ser perpetrado desde las instituciones del Estado, en este caso, debido a la convergencia de intereses con el crimen organizado. Esta es la postura que mantienen las familias de los estudiantes desaparecidos y las organizaciones de derechos humanos y sociales que los respaldan (GIEI 2015).

En este trabajo se asume que ambas posiciones son complementarias, por tanto, incompletas. Por una parte, la primera posición no reconoce las fallas institucionales que han permitido la captura de porciones importantes del Estado por parte de los Grupos Delictivos Organizados (GDO), en este caso las instituciones municipales y de seguridad y justicia (Banco Mundial, 2007); y, la segunda tesis parece que exenta de esta responsabilidad a las instituciones del crimen organizado.

El argumento central es que este suceso representa una falla del entramado político-institucional o una falla de Estado (Bazúa 2003 y Gracida 2014).

3 Esta crisis de seguridad no sólo es un fenómeno local, también es una preocupación regional por su crecimiento en las últimas décadas en "los llamados países en desarrollo o de medianos y bajos ingresos, categoría que comprende a todos los de América Latina y el Caribe, [esto, conforme a] la información que surge de los estudios de las naciones Unidas sobre tendencias delictivas y funcionamiento de los sistemas de justicia penal y de las encuestas de victimización." (Dammert y Bailey 2005: 9).

4 De acuerdo con Fernando Bazúa (2003: 16), “en la expresión 'falla de estado', la palabra 'falla' se refiere a una situación en la que la intervención estatal, intentando mejorar un determinado estado de cosas social, sin embargo, no alcanza tampoco la eficiencia, ya sea porque no logra tal mejoramiento y, por tanto, gasta inútilmente los recursos públicos usados, o lo logra pero derrochándolos, o lo logra sin derrocharlos pero genera otros estados de cosas sociales también públicamente negativos (lo cual puede darse también en los dos casos anteriores agravándolos)”. Otro enfoque analítico, recurrente en América Latina y México, ubica a estas fallas estatales como
Ayotzinapa. Entre la fragilidad institucional y la violencia del crimen organizado

Gabino Solano Ramírez José Carlos Luque Brazán Hortensia Gracida González 
Por un lado, debido a las limitaciones del proceso democratizador para las instituciones locales; $y$, por otro, a los efectos no deseados de la denominada guerra contra el narcotráfico. El alcance del trabajo es exploratorio, es decir, sólo se mostrará las evidencias que, a nuestro parecer, orientan la premisa principal del presente trabajo.

Así, en primer lugar, se describen los elementos que explican la fragilidad de las instituciones estatales; en un segundo momento, se exponen los desafíos que imponen al Estado mexicano los GDO; en seguida, se realiza un breve recuento de los sucesos de Iguala desde la perspectiva aquí adoptada; finalmente, se enlistan las consideraciones preliminares.

\section{La fragilidad institucional}

Es ampliamente aceptado que la democratización del régimen político mexicano se confirmó con la derrota del Partido Revolucionario Institucional (PRI) en las elecciones presidenciales del año 2000. Este proceso significó el cierre de un ciclo político caracterizado por los siguientes elementos: 1) la presencia de un régimen presidencialista; 2) la hegemonía política del PRI durante setenta años; 3) un Estado fuerte, clientelar y corporativo; y 4) una cultura política clientelar y corporativa (Woldenberg 2006, Crespo 2006). Se construyó desde la opinión pública y la academia una imagen optimista sobre el desarrollo de la democracia en México, que caminó, esencialmente, por la vía electoral (Ortega 2006), dejando inconclusas las reformas de importantes áreas del Estado mexicano.

Desde el año 2000 se han hecho esfuerzos políticos e institucionales con el propósito de reformar las instituciones heredadas del régimen anterior, un proceso que se conoce genéricamente como Reforma del Estado. Un ejemplo de ello es la creación de la Comisión de Estudios para la Reforma del Estado, tras el triunfo de Vicente Fox en el año 2000. En 2007, se instituyó una curiosa Ley para la Reforma del Estado. ${ }^{5}$ En 2011, el Senado aprobó 14 modificaciones constitucionales que presentó Felipe Calderón y, al inicio del sexenio presidencial de Enrique Peña se inició el ciclo de las denominadas reformas de segunda generación en el marco del Pacto por México. ${ }^{6}$

muestras de un Estado fallido y la crisis de las democracias en esta región. Uno de los principales argumentos al respecto, sostiene que las crisis y fallas institucionales de los Estados no desarrollados (tercermundistas, subdesarrollados, periféricos) son el germen de una serie de "males" que afectan a la comunidad internacional, entre los que destacan: inseguridad, terrorismo, violencia, guerras civiles y flujos migratorios. Esos desequilibran a las naciones colindantes y alteran las relaciones económicas, sociales, políticas y culturales a nivel global (Gutiérrez 2010).

5 Curiosa en el sentido de aprobar una Ley que obliga a reformar la ley, finalmente sólo produjo una serie de propuestas de reforma constitucional. Para un panorama más amplio de este proceso véase el texto de Claudia Gamboa (2010).

6 El Pacto por México fue un acuerdo político impulsado por el Presidente Enrique Peña y firmado por tres partidos políticos: El Partido Revolucionario Institucional (PRI), Partido Acción Nacional (PAN) y el Partido de la Revolución Democrática (PRD), con el propósito de 
En el caso del cambio político en Guerrero, tras la primera alternancia en el ejecutivo local en 2015, también hubo un esbozo por introducir en la agenda política una versión guerrerense de la Reforma del Estado, con el propósito de "arraigar la democracia" (Ortega 2007). No hubo tal. Esta iniciativa sólo produjo reformas electorales que se homologaron a las reformas federales en esta materia, aprobadas en 2007.

Como se aprecia, tanto en el ámbito federal como local, el proceso de reformas ha seguido una ruta gradualista que no produjo un nuevo acuerdo integral para transformar el entramado institucional y normativo heredado del viejo régimen (Muñoz Ledo 2001). Por tal razón, el cambio político resultó ser insuficiente y descompensado (Morlino 1985); insuficiente porque persisten algunas zonas grises de la política nacional, sobre todo en los temas de la transparencia y rendición de cuentas en el ejercicio del poder político, la impunidad ante casos de corrupción, y el financiamiento de la política.

Según Transparencia Internacional, México se ubica entre los países peor evaluados en el Îndice de Percepción de la Corrupción. ${ }^{7}$ En este informe resaltan los niveles de estructuración y transparencia en las instituciones más relevantes de los Estados: "los partidos políticos, el Poder Legislativo y Judicial y la policía. Entre estas instituciones destaca sin lugar a dudas la primera, la cual en la mayoría de los países latinoamericanos analizados fue percibida como la más corrupta" (Turi 2014).

En cuanto a la impunidad, un estudio del Instituto Tecnológico de Monterrey (ITAM) señala que el 98,5 por ciento de los delitos cometidos en México quedan impunes, según el informe "de los 7,48 millones de delitos cometidos en el país en lo que va del año - tanto del orden federal como del comúnúnicamente se ha formulado una condena en relación al uno por ciento. Del total de delitos sólo se denuncia un 22 por ciento, lo que hace cerca de $64 \mathrm{mil}$ denuncias" ("El Informador" 2010). En este mismo sentido, conforme a los resultados del Informe País sobre la Calidad de la Ciudadanía en México (IFE 2014), el 66 por ciento de los mexicanos consideraba que las leyes del país se cumplen poco o nada, y apenas el 4 por ciento opinaba que las leyes se respetan en México, contra 29 por ciento que señalaba que no se respetan.

El cambio también ha sido descompensado porque los avances institucionales en el ámbito nacional no se corresponden con el atraso institucional en las estructuras de los poderes políticos locales: en el nivel municipal, considerado

impulsar tres reformas estructurales: La Reforma Financiera, la Reforma Educativa y la Reforma en Telecomunicaciones. Para mayor información se sugiere consultar el siguiente vínculo electrónico: http://pactopormexico.org.

7 De acuerdo con este indicador, en 2014 México ocupó el lugar 103 de los 175 países evaluados, destacando por contar con la peor calificación de los 34 países que forman la Organización para la Cooperación y Desarrollo Económico (OCDE). En cuanto a América Latina, México sigue en los últimos lugares, por abajo de Brasil, Uruguay y Chile. Consultado en el portal del Instituto Mexicano para la Competitividad A.C.: http://imco.org.mx/competitividad/indice-depercepcion-de-la-corrupcion-2014-via-transparencia-internacional/
Ayotzinapa. Entre la fragilidad institucional y la violencia del crimen organizado

Gabino Solano Ramírez José Carlos Luque Brazán Hortensia Gracida González 
el eslabón más débil del entramado institucional; en la representación legislativa que aún mantiene su dependencia de los ejecutivos locales a pesar de que se integran con una mayor pluralidad (Solano 2014); así como la precariedad de los poderes judiciales frente a las decisiones del ejecutivo. Esta situación refleja la vigencia de reglas que favorecen la centralidad de las decisiones políticas y la preeminencia de la rama ejecutiva de gobierno en el régimen político mexicano.

Estos déficits de la democratización resultaron evidentes ante la debilidad de las instituciones municipales para hacer frente, entre otras cosas, a los graves problemas de inseguridad pública que viven numerosas regiones del país. Aunque el fenómeno de la inseguridad no es de competencia estricta del poder municipal, se reconoce que no están cumpliendo con su función preventiva en materia de seguridad pública; y, al contrario, los GDO han encontrado en estas instituciones una vía de acceso al poder político para consolidar su control de los territorios que concentran los principales mercados de drogas en el país.

Los déficits democráticos se han trasladado a una disminución en el respaldo ciudadano a la democracia. De acuerdo con el Informe del Latinobarómetro (2013: 19), el apoyo a la democracia mexicana pasó del 59 por ciento en el año 2005 al 37 por ciento en 2013. En estas circunstancias se afirma que la construcción democrática y su consolidación siempre va a ser problemática e inconclusa (O’Donnell 2010: 13). En esa dirección, es conveniente argumentar que la construcción del Estado constitucional y democrático de derecho en América Latina, y específicamente en México (Durango 2007), ha sido un proceso inacabado, complejo y difícil, no sólo porque en muchas ocasiones no se tiene claridad acerca de cómo edificarlo, sino porque persisten obstáculos para que ese proceso se consolide, los cuales están relacionados con la reproducción de relaciones clientelares y corporativas, apetitos autoritarios, reformas estructurales que cancelan derechos laborales y adelgazan la participación del Estado en los procesos sociales, la corrupción y el alejamiento de la ciudadanía del espacio público. Aunque después de la ola democrática se introdujeron reformas para mejorar la rendición de cuentas y transparencia, su implementación no produjo las transformaciones sustantivas esperadas; tampoco los cambios al modelo económico lograron el crecimiento y desarrollo productivo esperado.

En suma, la fragilidad institucional de las estructuras de poder político en México - sobre todo en su ámbito local - tiene uno de sus orígenes en las limitaciones de su proceso democratizador: insuficiente y descompensado, lo cual es visible frente al gran desafío que significa la presencia de grupos delictivos organizados en entidades como Guerrero y Michoacán.

\section{La violencia y los GDO}

Los GDO que se disputan el control del mercado de drogas representan un gran desafío al Estado mexicano, una prueba para la capacidad de respuesta de las instituciones estatales. El panorama de inseguridad que viven varias 
regiones del país es crítico, si se considera el paulatino crecimiento de los indicadores delictivos de alto impacto. ${ }^{8}$ Entre las ciudades más afectadas por esta crisis, medida a través de los homicidios dolosos registrados por cada 100 mil habitantes, se ubican las tres más importantes de Guerrero: Acapulco, Chilpancingo e Iguala, quienes ocupan reiteradamente los primeros lugares en estos indicadores (SESNSP).

El inicio del crecimiento exponencial de este fenómeno puede ubicarse en la declaratoria de "Guerra contra el narcotráfico" que hizo el expresidente Felipe Calderón al principio de su gobierno en 2006, con el propósito de rescatar los espacios públicos del control criminal. Esta acción significó un cambio estratégico en la política estatal hacia la atención del narcotráfico, sin embargo, la ofensiva militar no podía sostenerse sin el fortalecimiento de las instituciones locales de seguridad y justicia. Esto no sucedió y las repercusiones no deseadas produjeron, entre otras cosas: el incremento de víctimas no involucradas en las organizaciones criminales, el rompimiento visible de espacios de comunicación entre el gobierno y los cárteles traficantes de drogas, y la balcanización de los territorios en disputa entre los GDO.

1. En cuanto al incremento de víctimas civiles, de acuerdo al Relator Especial de Naciones Unidas sobre ejecuciones extrajudiciales, sumarias y arbitrarias, durante el periodo de la denominada guerra contra el narco en México (2006 y 2014), han sucedido 102,906 homicidios intencionales, 4,055 denuncias ante la PGR por tortura, 26,798 personas desaparecidas, 8,595 personas detenidas arbitrariamente bajo la figura de arraigo, 27 asesinatos y 8 casos de desaparición forzada en contra de personas defensoras de derechos humanos, más de 80 periodistas asesinados y 17 desaparecidos, fosas clandestinas en al menos 14 entidades del país, la proliferación de autodefensas y policías comunitarios en 2013. Estas acciones contribuyeron a la creación de un clima de miedo y victimización que ha favorecido, entre otras cosas, el desplazamiento forzado de personas, afectando a 287.358 personas en 15 estados del país. El mayor número de desplazados internos tienen su origen en Guerrero (21,5\%), seguido por Sinaloa (16\%), Michoacán (14\%), Tamaulipas (12\%) y Chiapas (7,7\%), (Rubio y Pérez Vázquez 2016).

Otro indicador de este fenómeno son las personas desaparecidas o no localizadas, de acuerdo con el Registro Nacional de Datos de Personas Extraviadas o Desaparecidas (RNPED), del SESNSP, hasta marzo del 2015, se contabilizaron “25,821 personas 'no localizadas', de éstas, 10,836 desaparecidos corresponden al periodo de gobierno de Peña Nieto. La otra parte, es decir la mayoría, data de la administración de Felipe Calderón" (Goche 2015). En el caso de Guerrero, según este Registro, la cifra de desapareci-

8 Para el lector interesado en los detalles de estas estadísticas, véase los reportes mensuales del Secretariado Ejecutivo del Sistema Nacional de Seguridad Pública, disponible en: http://secretariadoejecutivo.gob.mx/index.php
Ayotzinapa. Entre la fragilidad institucional y la violencia del crimen organizado

Gabino Solano Ramírez José Carlos Luque Brazán Hortensia Gracida González 
dos al 20 de octubre del 2014 era de 406 casos, ocupando el lugar número 14 a nivel federal.

En síntesis, estos indicadores reflejan la gravedad de la crisis de seguridad pública en el país, propiciando, entre otras cosas, la desarticulación de los procesos sociales que favorecen la convivencia pacífica entre la sociedad mexicana, esto es, el tejido social.

2. Respecto a la ruptura del control político articulado en el ciclo político anterior, durante el régimen corporativo del $\mathrm{PRI},{ }^{9}$ se afirma que:

los narcotraficantes debían someterse a la autoridad de la clase politica y las autoridades priistas, lo que significaba que quienes producían y traficaban drogas debían transferir la mayor parte de sus ganancias a las élites formales que controlaban a las instituciones impuestas por el PRI. En varios casos esas mismas elites eran las que se encargaban directamente del tráfico, como ocurrió en Sinaloa y Tamaulipas (...) con la alternancia democrática, esos mecanismos se debilitaron. (Duncan 2014: 179-180)

De este modo, los espacios de comunicación dieron paso a la confrontación. El Estado recurrió al ejército para enfrentar la capacidad bélica de las organizaciones criminales, una institución que no estaba totalmente preparada para garantizar la seguridad pública en el país ni para actuar con apego a los derechos humanos de la población. La intervención ha sido costosa para la institución militar, en términos de legitimidad, por los denominados "daños colaterales" que ha sufrido la sociedad mexicana por esta guerra, y la contaminación de algunos de sus cuadros militares que han sido cooptados por organizaciones criminales.

3. En el mismo sentido, el enfrentamiento cruzado entre los carteles criminales por el control de plazas y territorios y el que sostenían las fuerzas policiales y militares con ellos, dio lugar a un proceso de "balcanización":

favorecido por la captura de los líderes más importantes de los principales cárteles de las drogas en el país en el último decenio, lo que ha permitido que los líderes locales construyan su propia red delictiva en las localidades que tienen bajo su control, o son aprovechadas por las bandas rivales para capturar estos territorios. Así, el debilitamiento de las grandes organizaciones ha dado lugar a nuevos grupos locales con fronteras de influencia difusa y variante en el corto plazo, lo que ha convertido a buena parte del territorio guerrerense en 'zonas de caza', espacio de confrontaciones violentas entre bandas criminales por el control de localidades, ciudades o municipios. (Solano 2016)

9 En este sentido, la alternancia política en México tuvo una consecuencia no deseada, se rompió el pacto corporativo que los carteles de criminales sostuvieron con la vieja élite gobernante. 
Este proceso ha dado lugar en Guerrero a numerosas células del crimen organizado. Eduardo Guerrero (2014) ubica a 22 organizaciones, grupos locales que son subdivisiones o células de las grandes organizaciones nacionales como "los hermanos Beltrán Leyva, La Familia Michoacana, el Cártel JaliscoNueva Generación o Los Caballeros Templarios". ${ }^{10}$

La suma de estos efectos no deseados de la ofensiva militar contra el narcotráfico ha generado la mayor crisis de seguridad en el país, agravada en los ámbitos institucionales locales, el eslabón más débil de los poderes estatales.

\section{La fragilidad de las estructuras de gobierno municipal frente a los GDO}

Debido a los espacios de fragilidad institucional en el ámbito local, paulatinamente los cárteles criminales han incrementado su influencia política en los territorios que controlan para el comercio de drogas y otras actividades delictivas. La fragilidad de las autoridades municipales frente a los GDO ha sido reconocida por la Asociación de Autoridades Locales de México A.C. (AALMAC): ${ }^{11}$

La AALMAC, en sus 17 años de existencia ha señalado desde hace tiempo las debilidades estructurales y el agotamiento del modelo municipal: ha denunciado la infiltración y operación de la delincuencia en sus territorios y no ha sido atendida por los otros órdenes de gobierno. Incluso han pagado con su vida decenas de alcaldes, funcionarios y policías municipales - ninguno aclarado -. El doble centralismo que se padece ha cerrado la posibilidad de fortalecer ese ámbito de gobierno. (Zavala y Nácar 2014)

Para el Trasnational Institute la mayor influencia del narcotráfico en las estructuras de gobierno es posible por la corrupción, y sucede "en países como Colombia o México, [...] en el marco de las vinculaciones que buscan estas organizaciones - allá llamadas cárteles - con autoridades de gobierno, directamente, para lograr ciertas concesiones", (Soberón 1997).

Las rutas de esta colonización han sido a través del reclutamiento de la clase política gobernante, en los procesos de selección de candidaturas, o también sucede en el ejercicio del gobierno, a partir de la amenaza sistemática contra los funcionarios de los gobiernos locales.

10 "El Financiero", 17.05.2015, disponible en: http://www.elfinanciero.com.mx/nacional/elchapo-va-por-mas-poder-especialistas.html. Para un panorama más amplio de este mosaico de organizaciones véase a Solano (2016).

${ }^{11}$ Estas declaraciones fueron publicadas por la AALMAC en un desplegado el 24 de noviembre del 2014 en el diario "La Jornada".
Ayotzinapa. Entre la fragilidad institucional y la violencia del crimen organizado

Gabino Solano Ramírez José Carlos Luque Brazán Hortensia Gracida González 
Así, se han registrado numerosos casos de denuncias judiciales y encarcelamientos de alcaldes municipales, efectuadas por la Procuraduría General de la República, por su presunta relación con organizaciones delictivas, sobre todo en dos de las entidades con mayores niveles de presencia de GDO: Michoacán y Guerrero. En el caso de Michoacán - la entidad que marcó el inicio de la denominada "Guerra contra el narcotráfico" que inició el expresidente Felipe Calderón en 2006 -, durante el llamado "michoacanazo" de 2009, 11 presidentes municipales fueron procesados, y en 2014 "habían sido procesados y encarcelados ocho alcaldes por su probable relación con miembros del cartel de los Caballeros Templarios;" 12 mientras que en Guerrero a 2015 habían sido detenidos cuatro alcaldes, tres expresidentes municipales y uno en funciones, ${ }^{13}$ por vínculos con el cartel Guerreros Unidos y la Familia Michoacana. Uno de ellos es el exalcalde de Iguala, José Luis Abarca.

En cuanto a las agresiones que han sufrido funcionarios y políticos locales por parte de las organizaciones delictivas, Solano (2016) hace un recuento de este fenómeno para el caso de Guerrero, sumando a mayo de 2016, “147 incidencias violentas (63 homicidios, 40 secuestros y 44 amenazas o atentados) contra actores políticos que ocupaban o aspiraban a ocupar un cargo político o de representación, formaban parte de los equipos de campañas de los candidatos o eran dirigentes partidistas".

Estas fragilidades han contribuido a una mayor percepción de desconfianza ciudadana hacia las autoridades municipales y la democracia. De acuerdo con Hortencia Gracida (2014), el 67 por ciento de los guerrerenses no confían en sus alcaldes y sólo el 42 por ciento confían "totalmente o en parte" en la democracia local, un nivel de aceptación ligeramente mayor al promedio nacional del 37 por ciento en 2013. Así, la insatisfacción ciudadana por los graves problemas sociales que se viven en Guerrero ha sido trasladada a una insatisfacción con la democracia.

En los apartados previos se han explorado las razones de las fragilidades de las instituciones locales y el desafío de los GDO. Queda por indagar cómo estos grupos han colonizado importantes áreas del poder municipal. Las claves de este proceso se pueden encontrar en los sucesos de Iguala, Guerrero. Por tal razón tiene un alto valor simbólico, en seguida un breve recuento y posteriormente sus venas comunicantes.

12 "Han caído 146 funcionarios en Michoacán", publicado en el periódico "Excélsior", 20 de agosto de 2014, disponible en: http://www.excelsior.com.mx/nacional/2014/08/20/976979.

${ }^{13}$ Los alcaldes detenidos son: José Luis Abarca Velázquez, exalcalde de Iguala, por la desaparición forzada de los 43 normalistas de Ayotzinapa y su vínculo con el Cártel Guerreros Unidos; Feliciano Álvarez Mesino de Cuetzala del Progreso, por nexos con el Cártel La Familia Michoacana; Cesar Miguel Peñaloza Santana de Cocula, por su presunta relación con el Cártel Guerreros Unidos; y en febrero de 2016 el Presidente municipal de Cocula, Erick Ulises Ramírez (por presuntos vínculos con el Cártel Guerreros Unidos), (Solano 2016). 


\section{Ayotzinapa. Un breve recuento}

La desaparición de 43 estudiantes de la Normal Rural Isidro Burgos, el 26 de septiembre del 2014, significa un punto de inflexión en la relación sociedad civil-gobierno federal, sociedad civil-gobierno estatal y sociedad civil-gobierno municipal, porque muestra, en toda su magnitud, la convergencia de los gobiernos municipales con los carteles del crimen organizado en Guerrero, es decir, exhibe con claridad la estructura de control territorial y político establecida por los carteles criminales, al menos en este municipio guerrerense. Aquí un breve recuento de este acontecimiento. ${ }^{14}$

Los días previos a los hechos de Iguala tenían a la corriente dominante en el PRD (Nueva Izquierda, NI) con un gran optimismo. En las últimas elecciones para elegir al Consejo Nacional de este partido, celebradas el 7 de septiembre del 2014, su corriente había salido victoriosa y confirmaba el control que tenía de la estructura partidaria desde 2008, cuando asumió la dirigencia nacional Jesús Ortega, por una resolución del Tribunal Electoral del Poder Judicial de la Federación (TEPJF).

En el caso de Guerrero, los pronósticos también eran promisorios. Por una parte, la alianza que mantenían con el gobernador Ángel Aguirre - quien había inclinado la correlación de fuerzas locales hacia el PRD -, tenía amplias posibilidades de mantener la gubernatura, la mayoría congresional y los ayuntamientos, de cara a la elección de 2015; y, por otro, sus aliados locales (el Polo Guerrerense de Izquierda, PGI; la Coalición de Organizaciones Democráticas Urbanas y Campesinas, CODUC; y Nueva Mayoría, NM) habían ganado el proceso interno, logrando la mayoría de consejeros en disputa.

Entre los consejeros electos en Guerrero figuraba María de los Ángeles Pineda Villa, esposa del alcalde de Iguala, José Luis Abarca. De acuerdo con los registros del Instituto Nacional Electoral (INE), que organizó los comicios internos del PRD, Pineda Villa fue elegida como consejera estatal bajo el emblema de la CODUC, aliada de NI, liderada por el actual diputado local Sebastián de la Rosa.

Lo relevante de la postulación de Pineda Villa es que muestra, en el mejor de los casos, el autismo con el que se maneja la clase política frente a personajes que son cuestionados por su relación con grupos o actividades delincuenciales, como habían sido señalados el presidente municipal de Iguala y su esposa; pero, en el peor de los escenarios, refleja la complicidad con estas actividades delictivas. En el primer caso, lo que les motiva es la capacidad de llevar votos a la causa que abanderan; $y$, en el segundo, es mantener la influencia de las organizaciones criminales en los territorios municipales.

\footnotetext{
${ }^{14}$ Sobre lo sucedido en Iguala se han escrito innumerables páginas, desde diversas visiones analíticas. Para un recuento más amplio consultar el informe del Grupo Internacional de Expertos Independientes enviados a México por la Comisión Interamericana de Derechos Humanos, en acuerdo con el gobierno de la República.
}

Ayotzinapa. Entre la fragilidad institucional y la violencia del crimen organizado

Gabino Solano Ramírez José Carlos Luque Brazán Hortensia Gracida González 
Dado que no hay evidencia para afirmar lo contrario, los aliados políticos del matrimonio Abarca-Pineda, apuntalaron el control que éstos tenían en Iguala sin considerar las ominosas señales de sus acciones delictivas: las más conocidas, y por las cuales fue encarcelado tras los sucesos de Ayotzinapa, fueron los homicidios del líder perredista Arturo Hernández Cardona el 1 de junio de 2013 y de Justino Carbajal Salgado, exsíndico de Iguala, el 8 de marzo del mismo año. La participación de José Luis Abarca en el asesinato de Hernández Cardona trascendió a la opinión pública el 13 de noviembre de aquel año, en una declaración firmada ante Notario Público por uno de los testigos de este homicidio, difundida por la organización Red Solidaria Década contra la Impunidad. ${ }^{15}$ Finalmente, esta declaración fue presentada ante la Procuraduría General de Justicia del Estado de Guerrero (PGJG) el 12 de marzo de 2014 y fue requerida por la PGR hasta después de la desaparición de los 43 normalistas de Ayotzinapa. ${ }^{16}$ Además, diversos medios de comunicación habían dado cuenta de los nexos que tenían familiares de Pineda Villa con la organización de los hermanos Beltrán Leyva, quienes operaban en los estados de Morelos y Guerrero, constituyendo una red de alcaldes y policías municipales que permitían el tráfico de drogas y otros delitos. ${ }^{17}$ Con la desintegración de esta organización surgió Guerreros Unidos, la organización con la cual se vincula a José Luis Abarca.

De acuerdo con la revisión del expediente judicial de José Luis Abarca que realizaron estudiantes de la Maestría en periodismo y asuntos públicos del Centro para la Investigación y Docencia Económicas (CIDE), la participación de Abarca en el homicidio de Hernández Cardona muestra una "realidad escalofriante":

autoridades estatales y federales, instituciones de seguridad y justicia de todos los ámbitos, legisladores de Guerrero y federales sabían que Abarca era sospechoso de esos homicidios, y tal vez de otros. Lo sabían desde por lo menos un año antes de la noche de Iguala. Lo discutieron en reuniones privadas y se debatió en público, incluyendo la tribuna del Senado de la República. Si Abarca era presidente municipal de Iguala el 26 de septiembre de 2014, no fue por falta de pruebas en su contra, sino por la omisión deliberada de las autoridades facultadas para investigarlo y consignarlo. Y la tragedia de aquella noche tal vez podría no haber sucedido. La tardía detención del alcalde de Iguala por el asesinato de Hernández Cardona exhibe el estado del sistema de justicia

${ }^{15}$ Publicada en el periódico "La Jornada de Guerrero", disponible en: http://www.lajornadaguerrero.com.mx/2013/11/26/index.php?section=politica\&article=003n $1 \mathrm{pol}$

${ }^{16}$ Una amplia reconstrucción de este hecho fue publicada en la revista "Nexos" en su edición de octubre de 2015, conforme al expediente judicial del caso Abarca González, disponible en: http://www.nexos.com.mx/?p=26354

${ }_{17}$ Un recuento de esos señalamientos se publicó en "La Jornada” el 4 de noviembre de 2014 , disponible en: http://www.jornada.unam.mx/ultimas/2014/11/04/familiares-de-pineda-villasenalados-como-parte-de-guerreros-unidos-7493.html 
en México: procuradurías operativamente incapaces de armar casos sólidos $y$ atender un número creciente de expedientes que se acumulan, uno detrás de otro, en algún oscuro cajón por la escalada de la violencia; autoridades omisas ante intereses políticos, capaces de obstaculizar o, por el contrario, destrabar investigaciones judiciales. ("Nexos" octubre de 2015)

Finalmente, Abarca fue presidente municipal, a pesar de estos indicios. El control político que acumuló en Iguala le permitió preparar la postulación de su esposa para sucederlo al frente de este ayuntamiento. El escenario elegido para iniciar este proceso fue el informe anual de actividades que Pineda Villa daría como Presidenta del Sistema DIF de dicha ciudad la tarde del 26 de septiembre de 2014.

Aquel día, en medio de la fiesta de celebración del informe de Ángeles Pineda, hicieron su ingreso a la ciudad de Iguala un grupo de estudiantes de la Normal Rural de Ayotzinapa, su objetivo era realizar una colecta para contar con los recursos económicos necesarios para asistir a los eventos de conmemoración por la "Masacre de Tlatelolco" en la ciudad de México el 2 de octubre de 1968.

Todo sucedió como una historia de terror, cuya descripción no es el propósito de este trabajo. Los camiones en que se transportaban los estudiantes fueron baleados por agentes de la Policía Municipal y grupos de civiles, presuntos miembros de Guerreros Unidos, con un saldo de seis muertos y 43 estudiantes detenidos por los mismos agentes de la ley, todo realizado frente a miembros del 27 batallón del Ejército y policías federales. Ninguna de estas corporaciones actuó en consecuencia ante actos flagrantes y los 43 estudiantes desaparecieron hasta el día de hoy. Al día siguiente, 27 de septiembre, algunos importantes personajes del PRD guerrerense, manifestaron su apoyo al aún alcalde de Iguala, en especial, el diputado federal Sebastián de la Rosa. Durante tres días tanto el alcalde como su esposa permanecieron en Iguala, despachando tanto en las instalaciones del Palacio Municipal de Iguala e incluso José Luis Abarca tuvo tiempo de solicitar licencia a su cargo y despedirse con entrevistas a los medios de comunicación. Aquí tenemos el extracto de una de ellas que le realizó Ciro Gómez Leyva en Radio Fórmula, el día 29 de septiembre del 2014 a las nueve de la mañana:

Hasta el momento tengo entendido que hay 22 policías sujetos a investigación en el Puerto de Acapulco y no he tenido ninguna información al respecto, lo que yo sé que hubo un enfrentamiento y esto me he enterado por los medios escritos porque yo me encontraba en el Informe de la Presidente del DIF, en este momento me sumo a [...] que se investiguen los hechos y de que se castigue al culpable sea quien sea. (Gómez 2014)

Uno de los elementos que destaca en el caso Iguala-Ayotzinapa fue la lentitud de los servicios de seguridad pública para actuar. Recién el 28 de septiembre, dos días después de los hechos, la PGJG ordenó la detención de 22 poli-
Ayotzinapa. Entre la fragilidad institucional y la violencia del crimen organizado

Gabino Solano Ramírez José Carlos Luque Brazán Hortensia Gracida González 
cías municipales de Iguala. El 30 de septiembre el gobernador de Guerrero, Ángel Aguirre, llamó al alcalde de Iguala, José Luis Abarca, para solicitarle que demuestre que no tiene nada que ver con los eventos del 26 de septiembre. El alcalde de Iguala solicitó licencia al cargo por 30 días y después de ofrecer un discurso en las instalaciones del Palacio Municipal junto con su esposa, se dio a la fuga, cuatro días después del secuestro de los 43 estudiantes. El sistema de seguridad federal y estatal se paralizó durante todo este tiempo, lapso que fue clave para que los secuestradores contaran con todas las facilidades para desaparecer a los 43 estudiantes.

Los hechos que se dieron impulsaron a ciudadanos organizados y no organizados a expresar su rechazo a la desaparición de los estudiantes normalistas. Desde entonces han pasado 55 días y durante ese tiempo se han realizado tres marchas nacionales, 72 marchas en diversas ciudades de México y se han contabilizado 46 acciones de protesta en ciudades de América del Sur, Estados Unidos, Europa y Australia. Desde el 26 de septiembre las relaciones entre gobierno y sociedad civil se encuentran atravesando fuertes tensiones. Una de las acciones más importantes fue la que se dio en todo el país el 17 de octubre del presente año. Esta marcha fue multitudinaria en Guerrero, solo en Acapulco participaron más de 15 mil personas, además de diversas organizaciones sociales como: el Consejo de Ejidos y Comunidades Opositores a La Parota (Cecop) y el Movimiento Popular Guerrerense (MPG). También marchan normalistas de Chiapas y Oaxaca. Todos al grito de: “Ayotzi amigo, Acapulco está contigo!”, "Alerta, alerta, ¿quién lleva la batuta?, los estudiantes, no el gobierno que ejecuta”.

Estás acciones colectivas tuvieron la capacidad de influir positivamente en la renuncia del Gobernador de Guerrero, Ángel Aguirre, quien solicitó licencia a su cargo el 23 de octubre ("El Universal" 2014). El 31 de octubre del 2014, se realizó otra marcha en Acapulco en dónde los manifestantes señalaban la inoperancia del gobierno para solucionar el tema de las desapariciones de los estudiantes de Ayotzinapa. Se observó, a lo largo de todas estas acciones colectivas, una interacción entre militantes con una experiencia de años en los movimientos sociales y la paulatina llegada de jóvenes sin una mayor experiencia en este ámbito. Ya para estas fechas es importante resaltar que las organizaciones sociales habían logrado posicionar la legitimidad de sus demandas y los 43 estudiantes de Ayotzinapa se convirtieron en un símbolo de unidad en torno a demandas como la creciente impunidad, la corrupción de las instituciones del Estado y la necesidad de establecer vínculos a nivel nacional e internacional. Sin embargo, la imagen de los 43 estudiantes fue el elemento catalizador de las protestas sociales, tanto en Acapulco, México y en el mundo. Es la expresión de la globalización de los estudiantes de Ayotzinapa y de las demandas de justicia de importantes sectores de la sociedad mexicana.

Como corolario a este apartado, es pertinente mostrar las versiones polares de este suceso: la versión oficial de la PGR y la que propuso la comisión que envió la CIDH, como preámbulo del argumento de este trabajo. 
a) De acuerdo con la PGR, los normalistas de Ayotzinapa llegaron a Iguala con el propósito de recolectar recursos y posteriormente continuar su viaje a la ciudad de México para participar en las manifestaciones del dos de octubre. Sin embargo, los normalistas fueron señalados, por un informante del grupo delictivo Guerreros Unidos, como integrantes del grupo criminal antagónico, Los Rojos, quienes pretendían tomar la plaza de Iguala, por lo cual se dio aviso a la policía municipal de esa ciudad. Como medida de contención, el alcalde Abarca Velázquez o el jefe de la policía municipal Felipe Flores, o ambos, dieron la orden de detener el avance de los estudiantes. Conforme a las versiones de cuatro autores materiales, los estudiantes, una vez detenidos, fueron llevados a diversos sitios de los municipios de Iguala y Cocula, donde fueron ejecutados. Posteriormente incineraron sus cuerpos en el basurero municipal de Cocula. Para eliminar cualquier tipo de evidencia, los restos de los estudiantes incinerados fueron recolectados y depositados en bolsas que arrojaron al río San Juan. Las evidencias encontradas en bolsas al fondo del río coinciden químicamente con las halladas en el basurero de Cocula. Denominada por el entonces Procurador General de la República, Jesús Murillo Karam, como la verdad histórica, se concluyó que los 43 estudiantes de la normal de Ayotzinapa fueron detenidos, asesinados e incinerados por haber sido confundidos como miembros del grupo delictivo Los Rojos. ${ }^{18}$

b) De acuerdo con la versión del GIEI, ${ }^{19}$ el informe de la PGR sobre lo sucedido en el basurero de Cocula es inconsistente o contradictorio, afirmando que, sobre la base de estudios científicos, los normalistas no fueron incinerados en el lugar antes citado. En el informe de esta comisión, están registradas 20 recomendaciones a la PGR, derivadas de su análisis sobre la desaparición de los 43 estudiantes normalistas. ${ }^{20}$ El informe del GIEI pone énfasis en la participación de las corporaciones de seguridad la noche del 25 y 26 de septiembre, pues tanto la Policía Federal, la Policía Ministerial del estado y el Ejercito tuvieron información y dieron seguimientos a las actividades de boteo de los estudiantes normalistas previo a los ataques, así como su conocimiento de la detención de normalistas en las barandillas municipales. A pesar de esto, las dependencias de seguridad pública estatal y federal no actuaron para defender la violación a los derechos humanos que se estaba efectuando, ni funcionaron los mecanismos de protección e investigación del estado de Guerrero. Se cuestionó la forma en

${ }^{18}$ Informe sobre los avances de las investigaciones del caso de los 43 estudiantes de Ayotzinapa realizadas por la PGR por diversos medios de comunicación.

${ }^{19}$ Informe Ayotzinapa del GIEI. Investigación y primeras conclusiones de las desapariciones y homicidios de los normalistas de Ayotzinapa, disponible en: https://rive.google.com/file/ d/0B1ChdondilaHeURxcXRMQTNiUHM/view?pref=2\&pli=1, fecha de consulta: 13.06.2016.

${ }^{20} 20$ recomendaciones del GIEI a la PGR sobre el caso Ayotzinapa, disponible en: http:// www.eluniversal.com.mx/articulo/nacion/politica/2016/05/1/entrega-giei-pgr-20-recomendaciones-sobre-caso-ayotzinapa, fecha de consulta: 13.06.2016.
Ayotzinapa. Entre la fragilidad institucional y la violencia del crimen organizado

Gabino Solano Ramírez José Carlos Luque Brazán Hortensia Gracida González 
que supuestamente fueron incinerados los cuerpos de los 43 estudiantes desaparecidos, debido a que no existían antecedentes del grupo delictivo Guerreros Unidos para este tipo de violencia. Además, resaltó un elemento que fue ignorado por la PGR, la presencia de un quinto autobús que fue “tomado" por los normalistas, con la presunción de que estaría trasladando drogas, de ser así - señalaban -, se explica el nivel de violencia con el que fueron atacados los estudiantes normalistas, dado que fortalecía la presunción de que tras ellos estaba el grupo delictivo Los Rojos. También resaltaron la estrecha coordinación y comunicación con una estructura central - no identificada plenamente - para la ejecución del operativo en contra de los normalistas.

En resumen, ambas versiones enfatizan una parte relevante que hizo posible este acontecimiento. La PGR centra su argumento en la disputa entre Guerreros Unidos y Los Rojos, mientras que el GIEI exhibe la participación de las instituciones de seguridad en estos sucesos en convergencia con la organización Guerreros Unidos. Así visto, las dos posturas complementan el panorama que incubó Ayotzinapa. Lo que falta en esta trama es explorar la parte política que facilitó su convergencia, cuyos trazos se esbozan en seguida, pero, sin duda, es una línea de investigación pendiente.

\section{Ayotzinapa. Los vasos comunicantes}

Como aquí se ha apuntado, Guerrero ha registrado recurrentes episodios de violencia perpetrados por corporaciones de seguridad. Durante mucho tiempo se atribuyó esta situación al control del poder político que tenía el PRI en los diferentes niveles de gobierno. Se pensaba que bastaba que este partido dejara el poder para que las cosas cambiara. Tal fue la utopía de la transición democrática en México. En el caso de Guerrero, la anhelada alternancia llegó a través del PRD en el año 2005, cinco años después de la alternancia en el gobierno federal. Se inauguraba entonces una coyuntura política que se prolongaría en los siguientes diez años bajo gobernantes postulados por el PRD, pero que no eran militantes de este partido: en 2005, Zeferino Torreblanca Galindo y, en el 2011, el expriista, Ángel Aguirre Rivero.

El reto de los gobiernos perredistas era inmenso: sacar del atraso político, social y económico que arrastraba la entidad. Nuevamente, con desaliento, se confirmó que la democracia no influyó automáticamente para resolver los grandes problemas que enfrentaba el Estado, aunque se instaló la pluralidad política, que no es una cosa menor. Además, los nuevos gobiernos enfrentaron una creciente complejidad política y social que los llevó a situaciones límite al ser desafiados por importantes movilizaciones sociales que reivindicaban la vigencia de sus derechos o el reclamo de nuevos. Entre otras causas por: a) el creciente aumento de la violencia criminal y sus vínculos con los gobiernos municipales, que se tradujo en la configuración de actores sociales 
movilizados en torno al tema de la seguridad comunitaria (Unión de Pueblos y Organizaciones del Estado de Guerrero, UPOEG; Coordinadora Regional de Autoridades Comunitarias, CRAC); b) la ejecución de proyectos económicos de gran alcance que enfrentaron la resistencia de los pueblos afectados (la presa La Parota y proyectos mineros); c) la implementación de la reforma educativa que enfrentó la oposición de los maestros disidentes aglutinados en la Coordinadora Estatal de Trabajadores de la Educación de Guerrero (CETEG), expresión local de la Coordinadora Nacional de Trabajadores de la Educación (CNTE). Estas expresiones habían participado en los procesos electorales como aliados del PRD, forjados en las luchas populares que acompañaron a este partido en la disputa del poder político al PRI.

De este modo, la alternancia política no cubrió las expectativas de desarrollo político y social que se habían generado en la entidad. Las viejas reglas del juego político se reprodujeron con relativa facilidad con el nuevo partido gobernante, es decir, el proceso de instauración democrática fue inacabado por la ausencia de un proceso integral de reforma a las instituciones del régimen anterior.

Un elemento relevante de la alternancia guerrerense fue que el gobernador electo no era formalmente miembro del partido ganador, lo cual se tradujo en una difícil relación entre el partido de gobierno y el titular del ejecutivo (Solano 2007, Ayora 2011), y que llevaría al divorcio político entre ambos y una creciente relación de desgobierno que no va a ser capaz de enfrentar los nichos autoritarios heredados de los anteriores gobiernos priistas (Licea 2011). En los hechos, el PRD no tuvo la capacidad de influir en las decisiones de gobierno. En este sentido, el accionar político del PRD se redujo a desarrollar "presiones clientelares y demandas reivindicativas de carácter programático, como la de crear la Comisión de la Verdad Para las Violaciones de los Derechos Humanos durante la Guerra Sucia en los años sesentas y setentas del siglo pasado en Guerrero." (Solano 2007: 96).

De este modo, el gobierno de la alternancia no avanzó en el proceso de instauración democrática, es decir, en la construcción de las nuevas instituciones locales que habrían de albergar la pluralidad política y que encaminara las expectativas de cambio que había generado en la sociedad guerrerense. El fracaso de este proceso se muestra en la preeminencia de la rama ejecutivo de gobierno sobre los otros poderes del estado - para el nuevo gobierno esta regla resultaba funcional para mantener su predominio político -, así como en la fragilidad de las instituciones locales para dar respuesta a las demandas sociales acumuladas y otras nuevas que emergían de la crisis de seguridad. El proceso democratizador no avanzó sustancialmente tras la alternancia política, la nueva clase gobernante se adaptó a las reglas políticas que criticó durante su época de oposición, postergando el fortalecimiento del andamiaje institucional. El resultado fue una redistribución del poder político en instituciones que funcionaban casi con las mismas reglas del periodo previo a la alternancia, es decir, poco cambió el panorama institucional guerrerense.
Ayotzinapa. Entre la fragilidad institucional y la violencia del crimen organizado

Gabino Solano Ramírez José Carlos Luque Brazán Hortensia Gracida González 
En estas condiciones de fragilidad institucional, los GDO encontraron en Guerrero espacios fértiles para ampliar sus esferas de control político y territorial que necesitan para el trasiego de drogas y otros delitos. Además, como se apunta antes, la ofensiva federal contra estos grupos pulverizó su presencia en buena parte del territorio estatal, agravando la crisis de seguridad pública que actualmente se vive en la entidad, cuyos costos aún son incuantificables, sólo se tienen los informes oficiales que ubican a Guerrero a la cabeza de los estados en indicadores de delitos de alto impacto.

Aunque no se tienen datos contundentes para afirmarlo, esta situación sólo es posible en un contexto institucional permisivo a la impunidad para quienes cometen delitos, sea desde el poder político o las organizaciones delictivas. Un ejemplo de ello es que sólo tienen una resolución judicial entre el 4 y el 6 por ciento de los delitos que se denuncian (LeClercq y Rodríguez 2016); así como por la infiltración de los GDO en las instituciones de justicia y seguridad pública, como lo muestra el caso emblemático de Ayotzinapa, cuando policías municipales convergen con los "sicarios" de Guerreros Unidos en la captura y desaparición de los 43 normalistas.

La colonización de los espacios institucionales por parte de los GDO pasó necesariamente por los mecanismos de acceso al poder político, es decir, el sistema electoral y el sistema de partidos. Por una parte, la competencia política crea incentivos entre la clase política para buscar fuentes de financiamiento privados que les permita mayor ventaja en la disputa electoral, por otra, los GDO tienen incentivos para financiar aspiraciones políticas que les permitan operar sus redes de comercio de drogas y otros delitos. Estos acuerdos colusorios operan con éxito por la ausencia de candados efectivos para la entrada de dinero a los procesos electorales, de nuevo la parte institucional. Es una gran zona gris de la política mexicana, de la cual sólo se especula y comenta informalmente, pues no hay suficientes elementos que comprueben esta convergencia. De lo que sí se tiene evidencias es de los efectos no deseados de estos acuerdos, traducidos en el incremento de la violencia contra actores políticos, que presuntamente suceden cuando estos actores incumplen acuerdos o porque hicieron acuerdos con los grupos antagónicos. Así lo muestra Gabino Solano (2016) para el proceso electoral de 2015 en Guerrero, quien encuentra una relación positiva entre estos dos fenómenos: disputas entre GDO y violencia contra actores políticos. Así, las disputas territoriales entre estas organizaciones son trasladadas a la confrontación electoral. Este argumento abre otra línea de investigación enfocada al análisis de la sistemática amenaza que enfrentan los actores políticos en contextos de violencias delincuencial, cuyo alcance escapa a los propósitos de este trabajo.

Hasta aquí se han explorado las variables que se considera que incubaron el acontecimiento denominado Ayotzinapa: el desafío de los GDO y la fragilidad institucional que no resolvió la democratización del régimen político. Para cerrar este ensayo es necesario precisar, a manera de conclusión, la idea central expuesta en el trabajo. 


\section{Ayotzinapa. Un caso abierto a la reflexión}

La tragedia de Iguala muestra gráficamente la colusión entre policías municipales y sicarios de la organización "Guerreros Unidos", es decir, la paulatina colonización, por parte de las organizaciones delictivas, de las instituciones municipales y corporaciones de seguridad y justicia. Para explicar este hecho, hay una versión oficial - una verdad histórica - expuesta por la PGR y una versión alternativa que sugiere el grupo de expertos de la CIDH. En estas explicaciones se encuentran las dos líneas que hicieron posible esta convergencia: la fragilidad institucional y la fortaleza de los GDO que operan en la entidad.

En este trabajo se argumenta que estas explicaciones son complementarias. Y se enfatiza en las causas que han hecho posible estas dos circunstancias. La primera es resultado de un inacabado proceso de instauración democrática, que ha permitido zonas grises del entramado institucional, desde donde los GDO han accedido al control de importantes espacios de poder político. Mientras que la segunda es reflejo de los efectos no deseados de la política federal para enfrentar el desafío de las organizaciones delictivas al Estado mexicano, entre otros, la balcanización del territorio guerrerense y la grave crisis delictiva que ha ocasionado la ofensiva militar y la confrontación entre los GDO. Así entendido, ambas circunstancias tienen su origen en fallas del Estado mexicano, la primera porque la clase política no se ha comprometido en profundizar la instauración y consolidación de la democracia mexicana, y la segunda porque la ofensiva militar no fue acompañada del fortalecimiento de las instituciones de seguridad pública, sobre todo locales, para resistir la respuesta de las organizaciones delictivas. Tal es la dimensión del problema que vino a evidenciar el caso Ayotzinapa.

Por último, el propósito de este trabajo fue explorar las líneas de convergencia que hicieron posible el acontecimiento denominado Ayotzinapa. El rastreo de un elemento estructural, como lo son las limitaciones del proceso democratizador en México, caracterizado como insuficiente y descompensado, y otro de coyuntura, relativo a la política de seguridad en el país, ofrece un panorama más amplio para entender lo sucedido en Iguala el 26 y 27 de septiembre de 2014. Pero también aporta elementos explicativos de la grave crisis de seguridad que vive esta entidad, así como un camino a retomar para atender las causas que la motivaron: profundizar en la reforma integral democrática del entramado institucional del Estado mexicano, que incluya la reorientación de la política de seguridad en el país.

Quedan abiertas nuevas rutas de análisis, como los acuerdos colusorios entre la clase política y los GDO, un tema vinculado a la influencia del dinero en la democracia, y la violencia que produce esta relación para los actores políticos; así como también profundizar en el estudio de los efectos no deseados de estos procesos, entre otros, las víctimas de esta confrontación.
Ayotzinapa. Entre la fragilidad institucional y la violencia del crimen organizado

Gabino Solano Ramírez José Carlos Luque Brazán Hortensia Gracida González 
Ayora L. (2011), Elección para gobernador del estado de Guerrero, "El Cotidiano", (167), pp. 59-66, disponible en: http://www.redalyc.org/pdf/325/32518403007.pdf, consultado el 23 de julio de 2014.

Banco Mundial (2007), Gobernabilidad democrática en México: más allá de la captura del Estado y la polarización social, Banco Mundial, México.

Bazúa F. (2003), Estado, mercado e interés público en sociedades en transición, ponencia preparada para el Seminario Regional "Política y políticas públicas en los procesos de reforma en América Latina: similitudes y diversidades", organizado por la CEPAL y por la FLACSO, sede México, en la Ciudad de México del 26 al 28 de noviembre de 2003.

Crespo J. (2006), El mexicano frente al poder, en: R. Figueroa Martínez (coord.), Instituto de Seguridad y de los Servicios Sociales de los Trabajadores del Estado (ISSSTE), México.

Dammert L. y Bailey J. (2005), Seguridad y reforma policial en las Américas. Experiencias $y$ desafíos, FLACSO/Siglo XXI Editores, México.

Duncan G. (2014), Más que plata o plomo. El poder político del narcotráfico en Colombia $y$ México, Debate,Colombia.

Durango G. (2007), Estado democrático de derecho - Estado constitucional de derecho: ¿tensión entre el desarrollo y garantía de los derechos fundamentales?, "Revista de Derecho", (28), pp. 88-111, disponible en: http://www.redalyc.org/articulo.oa?id=85102805, consultado el 30 de abril de 2014.

"El Universal" (2014), ¿Quiénes conforman el cártel de 'Los Rojos?, disponible en: http:// www.redpolitica.mx/nacion/quienes-conforman-el-cartel-de-los-rojos, consultado el 2 de noviembre de 2014.

"El Informador" (2010), La impunidad en México alcanza al 98.5\% de los delitos, disponible en: http://www.informador.com.mx/mexico/2010/247146/6/la-impunidaden-mexico-alcanza-al-985-de-los-delitos.htm, consultado el 12 de enero de 2015.

Gamboa C. (2010), Logros, avances y pendientes de la reforma del Estado. Análisis de las propuestas de reformas del Estado de 2000 y 2007 y reformas constitucionales realizadas en el periodo 2000-2009, febrero, México, disponible en: http://www.diputados.gob.mx/sedia/sia/ spi/SPI-ISS-03-10.pdf

Goche F. (2005), Tragedia nacional": 25 mil 821 personas desaparecidas en México, "Revista Contralínea", 26 de abril, disponible en: http://www.contralinea.com.mx/archivo-revista/ index.php/2015/04/26/tragedia-nacional-25-mil-821-personas-desaparecidas-en-mexico/, consultado el 12 de junio del 2016.

Gómez C. (2014), Entrevista al Alcalde de Iguala, Radio Fórmula, disponible en: http://www. youtube.com/watch?v=FP22lztQ33E, consulta realizada el 5 de octubre del 2014.

Gracida H. (2014), Guerrero, ¿un estado fallido?, tesis de doctorado, México: IIEPA IMA UAGro.

GIEI, Grupo Interdisciplinario de Expertos Independientes (2015), Informe Ayotzinapa. Investigación y primeras conclusiones de las desapariciones y homicidios de los normalistas de Ayotzinapa, disponible en: http://8d5306c18b850ea7e0ac-65b9b7a2fa68b3c92f951010bb26a 4de.r54.cf2.rackcdn.com/pdf/Informe\%20ayotzi.pdf, consultado el 10 de septiembre de 2015.

Guerrero E. (2014), Guerrero en crisis, "Nexos", noviembre de 2014, Lantia Consultores, disponible en: http://www.nexos.com.mx/?p=24035 
Gutiérrez F. (2010), ¿Estados fallidos o conceptos fallidos? La clasificación de las fallas estatales y sus problemas, "Revista de Estudios Sociales", (37), pp. 87-104, disponible en: http://res. uniandes.edu.co/view.php/664/index.php?id=664, consultado el 5 de agosto de 2015.

IFE (2014), Informe País sobre la calidad de la ciudadanía en México, Instituto Federal Electoral (IFE) y el Colegio de México, disponible en: http://www.ine.mx/archivos2/s/DECEYEC/ EducacionCivica/Informe_pais_calidad_ciudadania_IFE_FINAL.pdf, consultado el 11 de octubre del 2015.

Latinobarómetro (2013), Informe 2013, Corporación Latinobarómetro, Chile, disponible en: www.latinobarometro.org/documentos/LATBD_INFORME_LB_2013.pdf

LeClercq Ortega J., Rodríguez Sánchez L. G. (2016), Índice Global de Impunidad en México, IGI MEX 2016, Fundación Universidad de las Américas, Puebla, México, obtenido de http:// www.udlap.mx/igimex/assets/files/igimex2016_ESP.pdf

Licea S. (2011), ¿Durmiendo con el enemigo? La relación del gobernador del estado de Guerrero con el PRD (estatal y nacional), "El Cotidiano", (167), pp. 99-110, disponible en: http://www. redalyc.org/pdf/325/32518403011.pdf, consultado el 18 de julio de 2014.

Morlino L. (1985), Cómo cambian los regímenes políticos, $1^{\text {a }}$ edición en español, Centro de Estudios Constitucionales, Madrid.

Muñoz Ledo, Porfirio (coord.) (2001), Comisión de Estudios para la Reforma del Estado, Conclusiones y propuestas, UNAM, México.

"Nexos" (2015), El primer asesinato de José Luis Abarca, disponible en: http://www.nexos.com. $\mathrm{mx} / \mathrm{p}=26354$

O’Donnell G. (2014), Democracia delegativa, en: Contrapuntos, Buenos Aires.

O’Donnell G. (2010), Democracia, agencia y estado: teoría con intención comparativa, Editorial Prometeo, Buenos Aires.

Ortega R. (coord.) (2007), Reforma democrática del estado de Guerrero. Análisis de opinión pública, Reporte técnico, Secretaría Técnica, Guerrero.

Ortega R. (2006), La transición votada, IIEPA IMA UAGro - Quadrivium, México.

PGR, Procuraduría General de la República (2015), Informe del caso Iguala. Estado que guarda la investigación de los hechos del 26 y 27 de septiembre del 2014, Iguala, Guerrero, disponible en: https://www.gob.mx/cms/uploads/attachment/file/101810/INFORME_CASO_IGUALA_2JUNIO-2016.pdf

Romero Ortiz M. V., Loza López J., Machorro Ramos F. (2013), Violencia del crimen organizado relacionada a los sectores económicos en México. Una propuesta de categorización, POLIS, "Revista Latinoamericana", 12, disponible en: http://www.redalyc.org/articulo. oa?id=30529678028.

Rubio Díaz Leal L., Pérez Vázquez B. (2016), Desplazados por violencia: la tragedia invisible "Nexos", enero, p. 33.

Soberón R. (1997), Corrupción, narcotráfico y fuerzas armadas: una aproximación para América Latina, disponibleen:http://www.tni.org/es/article/corrupci\%C3\%B3n-narcotr\%C3\%A1ficoy-fuerzas-armadas-una-approximaci\%C3\%B3n-para-am\%C3\%America-latina, consultado el 1 de mayo de 2014.

Solano, Gabino. (2016). La elección en Guerrero ante los desafíos de las violencias. En Tejera, Héctor, Rodríguez Emanuel y Castro Pablo, El momento que vivimos en la democracia mexicana. Procesos locales y nacionales a partir de las elecciones 2015. México: UAM-UG (en editorial).
Ayotzinapa. Entre la fragilidad institucional y la violencia del crimen organizado

Gabino Solano Ramírez José Carlos Luque Brazán Hortensia Gracida González 
Solano G. (2014), Desempeño institucional y político en los congresos locales: Guerrero, Sonora y Durango, MAPorrúa-UAGro, México.

Solano G. (2007), Guerrero: gobierno y partido gobernante (PRD), “El Cotidiano”, 22, (145), pp. 88-96, disponible en: http://www.redalyc.org/pdf/325/32514511.pdf, consultado el 9 de julio de 2014.

Transparencia Internacional (2013), Índice de percepción de la corrupción, disponible en: http://cpi.transparency.org/cpi2013/results/, consultado el 12 de octubre de 2014.

Turi A. (2014), Se mantienen altos niveles de corrupción en América Latina, disponible en: http://es.panampost.com/ana-lia-turi/2013/12/04/se-mantienen-altos-niveles-decorrupcion-en-america-latina/, consultado el 12 de mayo de 2015.

Woldenberg J. (2006), Partidos y elecciones en México, en: En voz alta. Testimonios de medio siglo, R. Figueroa Martínez (coord.), Instituto de Seguridad y de los Servicios Sociales de los Trabajadores del Estado (ISSSTE), México.

Zavala M., Nácar J. (2014), Impunes, 63 asesinatos de alcaldes en México. "24 Horas", disponible en: http://www.24-horas.mx/impunes-63-asesinatos-de-alcaldes-en-mexico/, consultado el 3 de diciembre de 2014. 